\title{
Nodal recurrence in the lateral neck after total thyroidectomy with prophylactic central neck dissection for papillary thyroid cancer
}

\author{
Marcin Barczyński • Aleksander Konturek • \\ Malgorzata Stopa $\cdot$ Wojciech Nowak
}

Received: 23 June 2013 / Accepted: 21 October 2013 / Published online: 9 November 2013

(C) The Author(s) 2013. This article is published with open access at Springerlink.com

\begin{abstract}
Purpose The aim of this study was to examine risk factors for nodal recurrence in the lateral neck (NRLN) in patients with papillary thyroid cancer (PTC) who underwent total thyroidectomy with prophylactic central neck dissection (TT + pCND). Methods This was a retrospective cohort study of patients with PTC who underwent TT + pCND. Data of all patients treated over a 10-year period (between 1998 and 2007) were analysed. The primary outcome was prevalence of NRLN within the 5-year follow-up after initial surgery. Predictors of NRLN were determined in the univariable and multivariable analysis.

Results Of 760 patients with PTC included in this study, 44 $(6.0 \%)$ developed NRLN. In the univariable analysis, the following factors were identified to be associated with an increased risk of NRLN: positive/negative lymph node ratio $\geq 0.3$ (odds ratio $(\mathrm{OR}) 14.50,95 \%$ confidence interval (CI) 7.21 to $29.13 ; p<0.001$ ), central lymph node metastases (OR 7.47, $95 \%$ CI 3.63 to $15.38 ; p<0.001$ ), number of level VI lymph nodes $<6$ in the specimen (OR $2.88,95 \%$ CI 1.21 to $6.83 ; p=0.016$ ), extension through the thyroid capsule (OR 2.55, $95 \%$ CI 1.21 to $5.37 ; p=0.013$ ), localization of the tumour within the upper third of the thyroid lobe (OR 2.35, $95 \%$ CI 1.27 to $4.34 ; p=0.006)$ and multifocal lesions (OR $1.85,95 \%$ CI 1.01 to $3.41 ; p=0.048$ ).

Conclusions Central lymph node metastases together with positive to negative lymph node ratio $\geq 0.3$ represent the strongest independent prognostic factors for the PTC recurrence in the lateral neck.
\end{abstract}

This study was presented at the 5th Workshop of the European Society of Endocrine Surgeons “Thyroid cancer", Berlin, Germany, May 23-25, 2013.

M. Barczyński $(\bowtie) \cdot$ A. Konturek $\cdot$ M. Stopa $\cdot$ W. Nowak

Third Department of General Surgery, Jagiellonian University

Medical College, 37 Prądnicka Street, 31-202 Kraków, Poland

e-mail: marbar@mp.pl
Keywords Prophylactic central neck dissection · Papillary thyroid cancer - Nodal recurrence in the lateral neck . Hypoparathyroidism $\cdot$ Recurrent laryngeal nerve injury

\section{Introduction}

Papillary thyroid cancer (PTC) is the most common endocrine malignancy and accounts for the majority of cases of thyroid cancer in iodine-sufficient areas of the world [1]. Most PTCs that are diagnosed are small and are generally regarded as being low risk, with little or no effect on mortality. It is widely accepted that total thyroidectomy (TT) is the procedure of choice for all PTCs above $10 \mathrm{~mm}$ in size [2, 3]. Lymph node metastases are a common finding in PTC, occurring in $20-50 \%$ of patients in the central compartment of the neck (level VI) and in 10-30\% in the lateral compartment of the neck (levels II -V) [4]. A strong expert consensus supported by evidence emerging from large studies is that when lymph nodes are palpable or visible on ultrasonography, en bloc compartment-oriented lymph node dissection should be performed, as opposed to the so-called berry picking of only the obviously abnormal nodes because the former approach is associated with a lower risk of recurrence and mortality despite earlier reports of no adverse effects on survival $[1,5,6]$. When there is no suspicion of metastatic disease to lymph nodes on imaging or palpation, prophylactic or elective central neck dissection (pCND) is a matter of debate [7-18]. Proponents of routine $\mathrm{pCND}$ argue that removing subclinical lymph node involvement reduces disease persistence. On the other hand, opponents of routine pCND underline the absence of evidence for improvement of long-term outcomes with resection of occult microscopic nodal metastases. Nevertheless, several respected organizations have recently recommended that TT plus pCND should be the standard 
operation for PTC $[2,3]$. However, it has been clearly shown that $55 \%$ of patients with metastatic level VI nodes identified after pCND also had metastatic nodes within levels III and IV, which would remain unrecognized without prophylactic lateral neck dissection (pLND) [19]. Thus, pCND together with pLND has a potential to provide optimized staging of $\mathrm{cN} 0$ PTC patients. Nevertheless, while pCND remains controversial, prophylactic LND is regarded as even more controversial and is rarely attempted.

The aim of this retrospective cohort study of patients undergoing surgery at our tertiary referral unit was to identify risk factors for nodal recurrence in the lateral neck in patients with PTC who underwent TT with pCND.

\section{Methods}

Study design and patient selection

This is a retrospective cohort study of 760 patients with PTC and clinically negative lymph nodes who were treated at the Third Department of General Surgery, Jagiellonian University Medical College in Krakow, Poland, between 1998 and 2007 and who were identified from the institutional computer-based register of thyroid surgery. The study group comprised patients who underwent TT with bilateral pCND and had a complete postoperative five-year follow-up. All the patients provided written informed consent for the storage and use of their data.

The inclusion criterion was a pathological diagnosis of PTC in a patient with lacking clinical evidence of nodal disease (cN0 status based on negative physical exam, negative preoperative neck ultrasound and no lymphadenopathy evident at surgery). The exclusion criteria were poorly differentiated thyroid carcinoma, incidental diagnosis of PTC, one-stage lymph node dissection based on therapeutic intent, distant metastasis at diagnosis, previous thyroid surgery, incomplete clinical data, follow-up information or histopathology report and ASA grade 4 (American Society of Anaesthesiology).

The following definition of clinically apparent lymph nodes necessitating therapeutic CND was used: palpable lymph nodes on physical examination, positive preoperative neck ultrasound and/or lymphadenopathy evident at surgery. The ultrasound criteria of lymph node malignancy recognized in this study as the exclusion criteria were the size of $1.0 \mathrm{~cm}$ or larger, cystic appearance, hyperechoic punctuations, absence of a hilum and peripheral vascularization. All the ultrasound examinations were performed by experienced radiologists trained in neck ultrasound.

The primary outcome measure was prevalence of nodal recurrence in the lateral neck within the 5-year follow-up after initial surgery. The secondary outcome measures were the prevalence of postoperative hypoparathyroidism and recurrent laryngeal nerve (RLN) injury. This project was approved by the institutional review board.

\section{Surgical technique}

Operations in both groups were performed by experienced endocrine surgeons, who followed a standardized technique of thyroidectomy described below. In both groups, the operation consisted of total extracapsular thyroidectomy with bilateral prophylactic level VI lymph node clearance (according to the American Thyroid Association classification) [2, 4]. The prelaryngeal lymph nodes, sitting directly anteriorly to the cricothyroid membrane between the cricothyroid muscles, were dissected at the time of mobilization of the thyroid pyramidal lobe and isthmus. The remaining level VI lymph nodes in the paratracheal and pretracheal spaces were dissected following thyroid gland removal. Medial and lateral dissection margins were defined using diathermy and surgical clips. The fibrofatty tissue in the midline was incised to expose the trachea down to the level of the brachiocephalic vessels inferiorly, and the medial border of the carotid artery was dissected down to the prevertebral fascia. The superior limit of dissection was at the level of the cricoid cartilage. The envelope of tissue containing the unilateral level VI lymph nodes was retracted medially and excised en bloc, using a combination of diathermy and surgical clips to free it from the prevertebral fascia, oesophagus and trachea. The thymus was transected at the level of the brachiocephalic vessels and the specimen was removed [17]. As soon as the ipsilateral level VI dissection was finished, the contralateral central neck dissection (CND) was undertaken to complete bilateral central neck clearance. In each patient, the RLNs were exposed and the branches of the superior and inferior thyroid arteries were divided close to the thyroid capsule (peripheral ligation). Intraoperative electrophysiological nerve integrity monitoring was used in selected patients treated in 2004-2007. The parathyroid glands were meticulously dissected from the thyroid gland and an effort was made to identify all four parathyroid glands and preserve as many as possible "in situ". Any inadvertently removed parathyroid gland found on inspection to be lying on the thyroid capsule or within the level VI compartment, any gland that was anatomically impossible to be preserved, as well as any devascularized gland were electively reimplanted into the sternocleidomastoid muscle.

\section{Postoperative follow-up}

All the clinical data and pathological reports were reviewed, and the TNM stage was assessed in each patient (based on the seventh edition of the AJCC staging system) [18].

Radioactive I-131 ablation (RAI) was given following thyroxine withdrawal to selected patients with thyroid 
tumours larger than $10 \mathrm{~mm}$ in diameter, when there were positive lymph nodes on pathology and/or tumour extension beyond the thyroid capsule and/or multifocal thyroid cancer.

All the patients in this study received postoperative suppressive levothyroxine treatment and thyroxine doses were adjusted to risk (to keep thyroid-stimulating hormone (TSH) below $0.1 \mathrm{mU} / \mathrm{L}$ for high-risk patients and from 0.1 to $0.3 \mathrm{mU} / \mathrm{L}$ for low-risk patients). A routine periodic clinical examination (every 3 months in the initial year and then at yearly intervals) was mandatory, including neck ultrasound, whole body scans and serum TSH (reference range, 0.4-4.2 mU/L) and basal thyroglobulin ( $\mathrm{Tg}$ ) levels with measurement of $\mathrm{Tg}$ antibodies. For detection of serum Tg levels, between 1998 and 1999, the DYNOtest (BRAHMS Diagnostica GmbH, Berlin, Germany) was used with a functional sensitivity of $1.0 \mathrm{ng} / \mathrm{mL}$, and the Immulite 2000 assay (Diagnostics Products Corporation, Los Angeles, CA, USA) was employed from the year 2000 onward with a functional sensitivity of $0.2 \mathrm{ng} / \mathrm{mL}$. Basal serum $\mathrm{Tg}$ levels above $2 \mathrm{ng} / \mathrm{mL}$ following TT with or without CND in a patient on levothyroxine suppressive therapy were classified as elevated values (denoting a high risk of recurrent disease).

The following criteria were used to define nodal recurrence: either pathological evidence of disease on excision or cytology or recurrent disease confirmed by two surveillance modalities (e.g. elevated $\mathrm{Tg}$ and whole-body scan). When possible, nodal recurrence was managed with surgical excision and repeat RAI therapy. The site of nodal recurrence and the type of neck dissection (central level VI or lateral levels II to $\mathrm{V}$, unilateral or bilateral) performed during revision surgery were reviewed and collected.

Indirect laryngoscopy was performed before surgery and on the first day after operation. RLN paresis was calculated for nerves at risk (there were 1,520 RLNs at risk in this study). In patients with RLN paresis, additional examinations were scheduled until vocal cord function recovered. Vocal cord paresis for more than 12 months after the operation was regarded as permanent.

The total serum calcium level (reference range 2.05-2.55 mmol/l) was measured $24 \mathrm{~h}$ after surgery and medical treatment was initiated if the concentration was below $2 \mathrm{mmol} / \mathrm{l}$. Medication was started on a prophylactic basis and no patient was allowed to develop symptoms of hypocalcemia. Calcium salts (1.5-3.0 $\mathrm{g} \mathrm{Ca}^{2+}$ daily) were administered when the total serum calcium level was in the range $1.8-2.0 \mathrm{mmol} / \mathrm{l}$ and calcium plus calcitriol $(0.25-1.0 \mu \mathrm{g} /$ day $)$ when it was below $1.8 \mathrm{mmol} / \mathrm{l}$. Serum calcium, serum phosphate and intact parathyroid hormone (iPTH; chemiluminescence assay, normal range $10-65 \mathrm{ng} / \mathrm{l}$, detection limit $4.4 \mathrm{ng} / \mathrm{l}$ ) levels were determined at 4 weeks after thyroidectomy. Hypocalcemia was defined as a total serum calcium level below $2.0 \mathrm{mmol} / 1$, irrespectively of the iPTH level. A serum calcium level below $2.0 \mathrm{mmol} / \mathrm{l}$ with a subnormal serum $\mathrm{PTH}$ level (below $10 \mathrm{ng} / \mathrm{l}$ ) was defined as transient hypoparathyroidism if restored to normal value within 12 months following withdrawal of oral calcium or calcium plus calcitriol therapy. Persistent hypocalcemia with the serum iPTH level below $10 \mathrm{ng} / \mathrm{l}$ for more than 12 months after surgery, requiring substitution with calcium with or without calcitriol, was regarded as permanent hypoparathyroidism.

\section{Statistical analysis}

Data are presented as mean with $95 \%$ confidence interval (CI), unless stated otherwise. The statistical significance of categorical variables was evaluated by the $\chi^{2}$ test, whereas the Student's $t$ test was used for the analysis of continuous variables. Odds ratios (ORs) with $95 \%$ CI were calculated for categorical variables. Univariable and multivariable logistic regression analyses were performed to identify predictors of the risk of nodal recurrence during the 5-year follow-up. Variables considered for the univariable analysis were gender, age, body mass index, smoking, tumour size, tumour localization in the upper third of the lobe, multifocal disease, extrathyroid extension, positive level VI lymph nodes, the number of level VI lymph nodes, positive/negative lymph node ratio, metachronous distant metastasis and RAI treatment. Variables achieving statistical significance at 0.1 level in the univariable analysis were included in the multivariable analysis. A backward variable selection procedure with the cutoff at $p<0.05$ was used to identify independent predictors of nodal recurrence during the 5-year follow-up. All the data were prospectively collected and stored in our computerbased institutional register of thyroid surgery and finally retrospectively analysed by a statistician. Statistical analyses were performed with Statistica ${ }^{\circledR} 10$ for Windows ${ }^{\circledR}$ (StatSoft, Krakow, Poland).

\section{Results}

Of 9,327 patients referred for thyroid surgery during the study period, 987 (10.6\%) had PTC and were potential candidates for the study. Two hundred twenty-seven patients did not meet the inclusion criteria (147 patients had incidental diagnosis of PTC, 51 patients underwent therapeutic CND, 4 patients had poorly differentiated thyroid cancer, 4 patients had distant metastasis at diagnosis) and 21 had incomplete histopathology or follow-up data, leaving 760 patients who were finally included in this study (Fig. 1). There were 624 women and 136 men with a mean age of 53.1 years at diagnosis (95\% CI, 51.88-54.32). All the patients in this study underwent TT with bilateral pCND ( $n=760)$ for staging of PTC. The mean number of lymph nodes in a surgical specimen following TT with pCND was 6.8 (median 7, range 4-21). Clinical and pathologic 
characteristics of patients analysed in this study are presented in Table 1.

RAI therapy was used in 618 of $760(81.3 \%)$ patients in this study. All 258 (33.9 \%) patients with positive lymph nodes following pCND received RAI. The mean cumulative dose of I-131 was $152.4 \mathrm{mCi}(95 \% \mathrm{CI}, 135.68-169.12)$.

The mean follow-up of the patients was 61.7 months (median 60, range 60-68) and $33(4.3 \%$ ) patients were lost to follow-up, whereas $7(0.9 \%)$ patients died during the study period.

\section{Primary outcomes}

Of 760 patients with PTC included in this study, 44 (6.0\%) developed nodal recurrence in the lateral neck during the 5 -year postoperative follow-up.

Overall, 48 patients $(6.3 \%)$ developed nodal recurrence ( $n=3$ within level VI, $n=41$ within levels II to IV, $n=3$ within levels II to VI, $n=31$ ipsilateral, $n=15$ contralateral and $n=2$ bilateral). Recurrences from skip metastases were identified in $10(2.0 \%)$ of 502 patients with negative level VI nodes following $\mathrm{pCND}$, while the remaining 34 (13.2\%) cases of nodal recurrence in the lateral neck were diagnosed in 258 patients with positive level VI nodes following CND $(p<0.001)$. All the patients who recurred were treated with surgery, which was followed by RAI therapy.
Nodal recurrence occurred among 8 (5.6\%) of 142 patients who did not receive RAI therapy versus 40 of 618 (6.5\%) patients who received RAI therapy $(p=0.711)$.

In the univariable analysis, male gender, tumour localization in the upper third of the lobe, multifocal disease, tumour extension through the thyroid capsule, positive level VI lymph nodes, number of level VI lymph nodes $<6$ in the specimen and positive to negative lymph node ratio $\geq 0.3$ predicted the nodal recurrence in the lateral neck (Table 2). In the multivariable analysis, positive/negative lymph node ratio $\geq 0.3$ (OR 14.50, $95 \%$ CI 7.21 to 29.13; $p<0.001$ ) and central lymph node metastases (OR 7.47, $95 \%$ CI 3.63 to $15.38 ; p<0.001$ ) were identified to be associated with an increased risk of nodal recurrence in the lateral neck.

\section{Secondary outcomes}

Basal serum thyroglobulin level below $2 \mathrm{ng} / \mathrm{mL}$ was observed in 718 (94.5\%) patients, while mean basal serum thyroglobulin level was $0.4 \mathrm{ng} / \mathrm{mL}$ (95\% CI, 0.10-0.70) after TT with pCND during the 5-year follow-up. Serum Tg antibodies were detected in 81 (10.7\%) patients after TT without pCND.

Transient hypoparathyroidism was observed in 243 (32.0\%) patients, while permanent hypoparathyroidism at 1 year after surgery was diagnosed in $17(2.2 \%)$ patients. Parathyroid reimplantation was undertaken in 359 (47.2\%)
Fig. 1 Flow diagram of the study. $p C N D$ prophylactic central neck dissection, $N R L N$ nodal recurrence in the lateral neck

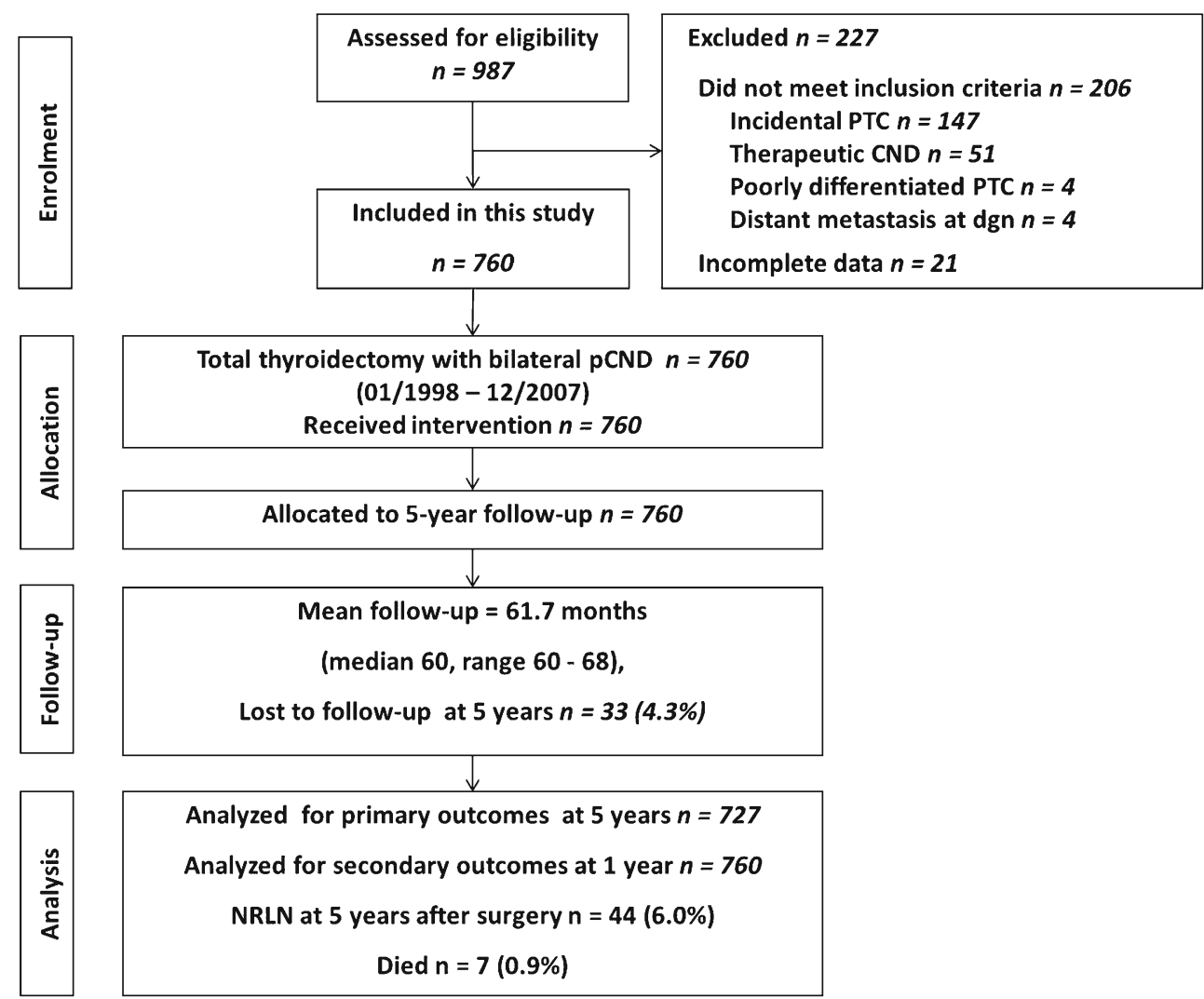


Table 1 Clinical and pathological characteristics of 760 patients analysed in this study

\begin{tabular}{lc}
\hline Characteristics & TT with pCND $(n=760)$ \\
\hline Gender & \\
Male & $136(17.9)$ \\
Female & $624(81.1)$ \\
Age at diagnosis, years & \\
$<45$ & $312(41.1)$ \\
$\geq 45$ & $448(58.9)$ \\
pT stage & \\
pT1a & $228(30.0)$ \\
pT1b & $167(22.0)$ \\
pT2 & $270(35.5)$ \\
pT3 & $79(10.4)$ \\
pT4a & $16(2.1)$ \\
pT4b & $0(0)$ \\
Multifocal disease (yes) & $289(38.0)$ \\
Tumour in the upper third of the lobe (yes) & $266(35.0)$ \\
Extension through thyroid capsule (yes) & $84(11.1)$ \\
Metachronous distant metastasis (yes) & $4(0.5)$ \\
TNM stage ${ }^{a}$ & \\
I & $452(59.5)$ \\
II & $83(10.9)$ \\
III & $221(29.1)$ \\
IV & $4(0.5)$ \\
\hline
\end{tabular}

Values represent numbers (percent), unless indicated otherwise; $\chi^{2}$ test for all values

$T T$ total thyroidectomy, $p C N D$ prophylactic central neck dissection

${ }^{a}$ TNM stage according to AJCC 2010 classification

patients. Inadvertent removal of parathyroid tissue was confirmed in 55 (7.2\%) of pathological reports. Unilateral temporary RLN injury was identified in 50 (3.3\%) of 1,520 nerves at risk, while permanent RLN palsy at 12 months after surgery was diagnosed in 21 (1.4\%) of 1,520 nerves at risk. Data are shown in Table 3.

All 44 patients with nodal recurrence in the lateral neck who underwent modified lateral neck dissection (clearance of levels II-V) had no permanent morbidity related to this procedure (one wound infection and one chyle leak treated conservatively).

\section{Discussion}

An area of ongoing controversy in the management of patients with PTC is the role of pCND [20]. The rationale for performing $\mathrm{pCND}$ on a routine basis includes reduced rates of central neck recurrence, reduced morbidity with secondary central neck lymphadenectomy, improved rates of postoperative athyroglobulinemia, improved staging of the disease and
Table 2 Univariable analysis of variables associated with nodal recurrence in the lateral neck during the 5-year follow-up

\begin{tabular}{|c|c|c|c|}
\hline \multirow[t]{2}{*}{ Characteristics } & \multirow[t]{2}{*}{$\begin{array}{l}\text { No. of } \\
\text { patients }\end{array}$} & \multicolumn{2}{|c|}{$\begin{array}{l}\text { Nodal recurrence in the } \\
\text { lateral neck during the } \\
5 \text {-year follow-up }(n=44)\end{array}$} \\
\hline & & $\begin{array}{l}\text { Odds ratio } \\
(95 \% \mathrm{CI})\end{array}$ & $p$ \\
\hline \multicolumn{4}{|l|}{ Gender } \\
\hline $\begin{array}{l}\text { Male } \\
\text { Female }\end{array}$ & $\begin{array}{l}136 \\
624\end{array}$ & $\begin{array}{l}2.27(1.17-4.41) \\
1.00\end{array}$ & 0.015 \\
\hline \multicolumn{4}{|l|}{ Age (years) } \\
\hline $\begin{array}{l}\geq 45 \\
<45\end{array}$ & $\begin{array}{l}448 \\
312\end{array}$ & $\begin{array}{l}1.01(0.54-1.87) \\
1.00\end{array}$ & 0.984 \\
\hline \multicolumn{4}{|c|}{ Body mass index $\left(\mathrm{kg} / \mathrm{m}^{2}\right)$} \\
\hline $\begin{array}{l}\geq 30 \\
<30\end{array}$ & $\begin{array}{l}119 \\
641\end{array}$ & $\begin{array}{l}1.02(0.44-2.35) \\
1.00\end{array}$ & 0.047 \\
\hline \multicolumn{4}{|l|}{ Smoker } \\
\hline $\begin{array}{l}\text { Yes } \\
\text { No }\end{array}$ & $\begin{array}{l}251 \\
509\end{array}$ & $\begin{array}{l}1.05(0.55-2.00) \\
1.00\end{array}$ & 0.877 \\
\hline \multicolumn{4}{|l|}{ Tumour size } \\
\hline $\begin{array}{l}\geq 10 \mathrm{~mm} \\
<10 \mathrm{~mm}\end{array}$ & $\begin{array}{l}593 \\
228\end{array}$ & $\begin{array}{l}1.33(0.64-2.73) \\
1.00\end{array}$ & 0.450 \\
\hline \multicolumn{4}{|c|}{ Tumour in the upper third of the lobe } \\
\hline $\begin{array}{l}\text { Yes } \\
\text { No }\end{array}$ & $\begin{array}{l}266 \\
494\end{array}$ & $\begin{array}{l}2.35(1.27-4.34) \\
1.00\end{array}$ & 0.006 \\
\hline \multicolumn{4}{|c|}{ Multifocal disease } \\
\hline $\begin{array}{l}\text { Yes } \\
\text { No }\end{array}$ & $\begin{array}{l}289 \\
471\end{array}$ & $\begin{array}{l}1.85(1.01-3.41) \\
1.00\end{array}$ & 0.048 \\
\hline \multicolumn{4}{|c|}{ Extension through thyroid capsule } \\
\hline $\begin{array}{l}\text { Yes } \\
\text { No }\end{array}$ & $\begin{array}{l}84 \\
676\end{array}$ & $\begin{array}{l}2.55(1.21-5.37) \\
1.00\end{array}$ & 0.013 \\
\hline \multicolumn{4}{|c|}{ Positive level VI lymph nodes } \\
\hline $\begin{array}{l}\text { Yes } \\
\text { No }\end{array}$ & $\begin{array}{l}258 \\
502\end{array}$ & $\begin{array}{l}7.47(3.63-15.38) \\
1.00\end{array}$ & $<0.001$ \\
\hline \multicolumn{4}{|c|}{ Number of level VI lymph nodes } \\
\hline $\begin{array}{l}<6 \\
\geq 6\end{array}$ & $\begin{array}{l}52 \\
708\end{array}$ & $\begin{array}{l}2.88(1.21-6.83) \\
1.00\end{array}$ & 0.016 \\
\hline \multicolumn{4}{|c|}{ Lymph node ratio (positive/negative) } \\
\hline $\begin{array}{l}\geq 0.3 \\
<0.3\end{array}$ & $\begin{array}{l}58 \\
702\end{array}$ & $\begin{array}{l}14.50(7.21-29.13) \\
1.00\end{array}$ & $<0.001$ \\
\hline \multicolumn{4}{|c|}{ Metachronous distant metastasis } \\
\hline $\begin{array}{l}\text { Yes } \\
\text { No }\end{array}$ & $\begin{array}{l}4 \\
756\end{array}$ & $\begin{array}{l}5.52(0.56-54.26) \\
1.00\end{array}$ & 0.142 \\
\hline \multicolumn{4}{|c|}{ Radioactive iodine treatment } \\
\hline Yes & 618 & $2.39(0.84-6.79)$ & 0.102 \\
\hline No & 142 & 1.00 & \\
\hline
\end{tabular}

$95 \%$ CI $95 \%$ confidence interval

improved stratification of RAI dosage [2, 20-24]. Nevertheless, these potential benefits are considered to be rather soft due to a paucity of the randomized controlled trials in this field indicating improvement in hard endpoints, such as disease-specific survival. The American Thyroid Association (ATA) estimated that a randomized trial to evaluate $\mathrm{pCND}$ in PTC would require 5,840 patients and cost an estimated US $\$ 15$ million and hence it is hardly feasible [13]. Two meta-analyses including mostly retrospective data have shown an absence of a clinically 
Table 3 Secondary outcomes

\begin{tabular}{lc}
\hline Characteristics & $\begin{array}{l}\text { TT with pCND } \\
(n=760)\end{array}$ \\
\hline Hypoparathyroidism, no. (\%) & $260(34.2)$ \\
Total & $243(32.0)$ \\
Transient (0-12 months postop.) & $17(2.2)$ \\
Permanent (above 12 months postop.) & $359(47.2)$ \\
Parathyroid reimplantation, no. (\%) & $55(7.2)$ \\
Parathyroids found in pathological report, No. (\%) & \\
Unilateral RLN injury, no. (\%) & \\
Total & $72(4.7)$ \\
Temporary (0-12 months postop.) & $50(3.3)$ \\
Permanent (above 12 months postop.) & $21(1.4)$ \\
Basal serum thyroglobulin level $<2$ ng/mL, no. $(\%)$ & $718(94.5)$
\end{tabular}

$\chi^{2}$ test for all values

TT with $p C N D$ total thyroidectomy with prophylactic central neck dissection

${ }^{\text {a }}$ Calculation for nerves at risk, not for patients (there were 1,520 nerves at risk in this study)

significant reduction in disease recurrence from $\mathrm{pCND}[25,26]$. Despite this, the revised ATA guidelines from 2009 recommended that pCND may be performed in patients with PTC with clinically uninvolved central neck lymph nodes, especially for advanced primary tumours (T3 or T4) [2]. Gyorki at al., in a critical appraisal of the available literature, demonstrated insufficient evidence to indicate that this extra procedure performed routinely leads to improvement in clinically meaningful endpoints [20].

Nevertheless, a recently published systematic review of imaging-guided and pCND for PTC found metastatic central lymph nodes in nearly half of all patients. The sensitivity of ultrasonography and computed tomography appeared to be poor for accurate staging of lymph nodes, ranging from 50 to $70 \%[27,28]$. In contrast, our institutional experience with pCND in cN0 PTC patients is encouraging [29]. Many other authors are also in favour of performing prophylactic neck dissection for optimization of staging of the disease $[2,10-12$, $16,17,19]$. In our institution, patients with cN0 PTC have been managed with TT and bilateral pCND for staging of PTC since 1998. When compared to historical controls treated in 1993-1997, who underwent total thyroidectomy alone, bilateral pCND for staging of the neck in PTC, followed by personalized adjuvant radioiodine treatment improved both the 10-year disease-specific survival and locoregional control without increasing the risk of permanent morbidity [29]. In addition, it was shown that locoregional control was significantly better for patients who had TT with pCND (94.5 vs. $87.6 \%$ at 10 years), and this was also the case among the group that did not receive RAI therapy [29].

In the present study, nodal recurrence in the central neck occurred only in 6 of $727(0.8 \%)$ patients during the 5-year follow-up after TT with bilateral pCND, including five cases on the right side of the neck (in the lymph nodes beyond the RLN) and one case on the left side of the central neck. Similar data were reported recently by Hartl et al. who analysed the influence of pCND on the rate of retreatment in cN0 PTC patients in the 5-year follow-up [30]. Of 246 patients who underwent TT alone $(n=91)$ or TT with pCND $(n=155)$, overall, 12 vs. $2 \%$ needed reoperation in the central neck, respectively $(p<0.001)$, with no difference in the prevalence of permanent morbidity [30]. Thus, in a long-term observation, a routine use of TT with pCND abolished the problem of possible reoperation in the central neck for persistent or recurrent nodal disease when compared to patients who underwent TT without pCND. In our previous study, it was shown that most locoregional recurrences occurred within level VI of the neck ( $67.6 \%$ of all relapses) within 10 years when pCND was not performed, but in a minority of patients $(26.7 \%$ of all relapses) when pCND was done at initial surgery [29].

The present retrospective study was performed in a large cohort of patients $(n=727)$ with $\mathrm{cN} 0$ PTC who completed the 5-year follow-up after TT with bilateral pCND performed in the years 1998-2007 and aimed at identifying risk factors for nodal recurrence in the lateral neck, which occurred in $6.0 \%$ of the patients. In the multivariable analysis, central lymph node metastases together with positive to negative lymph node ratio $\geq 0.3$ were identified to represent the strongest prognostic factors for PTC recurrence in the lateral neck. It is also of interest to note that patients with fewer than six lymph nodes in the surgical specimen had a higher rate of nodal recurrence in the lateral neck than those who had six lymph nodes or more in the pathology report. Thus, to appropriately stage the lymph nodes status in the central neck, at least six lymph nodes should be surgically removed and evaluated by a pathologist; otherwise, $\mathrm{pNx}$ status is warranted. Recurrences from skip metastases were identified in this cohort in $10(2.0 \%)$ of 502 patients with negative level VI nodes following pCND, while the remaining $34(13.2 \%)$ cases of nodal recurrence in the lateral neck were diagnosed in 258 patients with positive level VI nodes following CND $(p<0.001)$. Tumour localization in the upper third of the lobe was associated with an increased rate of nodal recurrence in the lateral neck in the univariable analysis, but not in the multivariable analysis. Similar data were also reported by others [29, 31-33]. Ricarte-Filho et al. looked for independent prognostic factors for recurrence among lymph node-positive patients using the multivariable analysis and showed more than three positive nodes to be associated with a shorter recurrence-free survival [34]. By contrast, patients under the age of 45 with fewer than three positive nodes had no recurrences even without the use of RAI [34].

The prevalence of central lymph node involvement in PTC is variable in published series, ranging from 30 to $70 \%$ $[25,26]$. Hartl et al. analysed 317 patients with PTC who 
underwent both pCND and pLND [19]. In this study, pN1 stage was $42 \%$ overall: $23 \%$ for unilateral pCND, $39 \%$ for bilateral pCND and $23 \%$ for pLND. Fifty-five percent of the patients staged $\mathrm{pN} 1$ had metastatic nodes in the lateral neck [19]. However, only few of the positive nodes in the lateral neck turn out to be clinically relevant in long-term observation. As indicated by the results of the present study, nodal recurrence in the lateral neck is tenfold less frequent $(6.0 \%)$ than the prevalence of lateral neck involvement reported in the literature $(55 \%)$. Therefore, the majority of patients with PTC undergoing TT with pCND, but no pLND, are likely to have occult nodal disease left behind in the lateral neck, yet recurrence rates are extremely low [35]. In case of recurrent nodal disease in the lateral neck, modified lateral neck dissection of levels II, III, IV and V can be done safely by experienced hands without any substantial risk of permanent morbidity $[30,31]$. Thus, in our opinion, pLND is not necessary for staging of the neck, as recurrences arising from skip metastases are extremely rare (2\%) and identification of PTC patients at an increased risk of recurrence in the lateral neck can be done based on staging of the central neck. In conclusion, it is important to acknowledge that central lymph node metastases together with positive to negative lymph node ratio $\geq 0.3$ represent the strongest independent prognostic factors for PTC recurrence in the lateral neck and patients meeting the above criteria should undergo strict surveillance.

Finally, it should be underlined that the safety of pCND is of utmost importance. At our institution, transient but not permanent hypoparathyroidism was more common in patients who had TT with pCND [29, 36], as described in other series from high-volume centres [37, 38]. However, the risk of permanent hypocalcemia appears to be significantly greater at lower volume centres and was reported to be as high as $16 \%$, which is not acceptable [38, 39]. This issue must be taken into consideration and $\mathrm{pCND}$ cannot be recommended for low-volume thyroid surgeons.

Open Access This article is distributed under the terms of the Creative Commons Attribution License which permits any use, distribution, and reproduction in any medium, provided the original author(s) and the source are credited.

\section{References}

1. Mazzaferri EL, Jhiang SM (1994) Long-term impact of initial surgical and medical therapy on papillary and follicular thyroid cancer. Am J Med 97:418-428

2. American Thyroid Association (ATA) Guidelines Taskforce on Thyroid Nodules and Differentiated Thyroid Cancer, Cooper DS, Doherty GM, Haugen BR, Kloos RT, Lee SL, Mandel SJ, Mazzaferri EL, McIver B, Pacini F, Schlumberger M, Sherman SI, Steward DL, Tuttle RM (2009) Revised American Thyroid Association management guidelines for patients with thyroid nodules and differentiated thyroid cancer. Thyroid 19:1167-1214
3. British Thyroid Association-BTA (2007) Guidelines for the management of thyroid cancer in adults. Available at: http:/www.britishthyroid-association.org/Guidelines. Accessed 21 June 2013.

4. American Thyroid Association Surgery Working Group, American Association of Endocrine Surgeons, American Academy of Otolaryngology-Head and Neck Surgery, American Head and Neck Society, Carty SE, Cooper DS, Doherty GM, Duh QY, Kloos RT, Mandel SJ, Randolph GW, Stack BC Jr, Steward DL, Terris DJ, Thompson GB, Tufano RP, Tuttle RM, Udelsman R (2009) Consensus statement on the terminology and classification of central neck dissection for thyroid cancer. Thyroid 19:1153-1158

5. Lundgren CI, Hall P, Dickman PW, Zedenius J (2006) Clinically significant prognostic factors for differentiated thyroid carcinoma: a population-based, nested case-control study. Cancer 106:524-531

6. Tisell LE, Nilsson B, Mölne J, Hansson G, Fjälling M, Jansson S, Wingren U (1996) Improved survival of patients with papillary thyroid cancer after surgical microdissection. World J Surg 20:854-859

7. Monchik JM, Simon CJ, Caragacianu DL, Thomay AA, Tsai V, Cohen J, Mazzaglia PJ (2009) Does failure to perform prophylactic level VI node dissection leave persistent disease detectable by ultrasonography in patients with low-risk papillary carcinoma of the thyroid? Surgery 146:1182-1187

8. White ML, Gauger PG, Doherty GM (2007) Central lymph node dissection in differentiated thyroid cancer. World J Surg 31:895-904

9. McHenry CR (2011) Prophylactic central compartment neck dissection for papillary thyroid cancer: the search for justification continues. Surgery 150:1058-1060

10. Roh JL, Park JY, Park CI (2007) Total thyroidectomy plus neck dissection in differentiated papillary thyroid carcinoma patients: pattern of nodal metastasis, morbidity, recurrence, and postoperative levels of serum parathyroid hormone. Ann Surg 245:604-610

11. Forest VI, Clark JR, Ebrahimi A, Cho EA, Sneddon L, Gao K, O'brien CJ (2011) Central compartment dissection in thyroid papillary carcinoma. Ann Surg 253:123-130

12. Hughes DT, White ML, Miller B, Gauger PG, Burney RE, Doherty GM (2010) Influence of prophylactic central lymph node dissection on postoperative thyroglobulin levels and radioiodine treatment in papillary thyroid cancer. Surgery 148:1100-1107

13. Carling T, Carty SE, Ciarleglio MM, Cooper DS, Doherty GM, Kim LT, Kloos RT, Mazzaferri EL Sr, Peduzzi PN, Roman SA, Sippel RS, Sosa JA, Stack BC Jr, Steward DL, Tufano RP, Tuttle RM, Udelsman R, American Thyroid Association Surgical Affairs Committee (2012) American Thyroid Association design and feasibility of a prospective randomized controlled trial of prophylactic central lymph node dissection for papillary thyroid carcinoma. Thyroid 22:237-244

14. Clark OH (2011) Thyroid cancer and lymph node metastases. J Surg Oncol 103:615-618

15. Shaha AR (2009) Prophylactic central compartment dissection in thyroid cancer: a new avenue of debate. Surgery 146:1224-1227

16. Poppadich A, Levin O, Lee JC, Smooke-Praw S, Ro K, Fazel M, Arora A, Tolley NS, Palazzo F, Learoyd DL, Sidhu S, Delbridge L, Sywak M, Yeh MW (2011) A multicenter cohort study of total thyroidectomy and routine central lymph node dissection for $\mathrm{cN} 0$ papillary thyroid cancer. Surgery 150:1048-1057

17. Grodski S, Cornford L, Sywak M, Sidhu S, Delbridge L (2007) Routine level VI lymph node dissection for papillary thyroid cancer: surgical technique. ANZ J Surg 77:203-208

18. Edge SB, Byrd DR, Compton CC, Fritz AG, Greene FL, Trotti A (eds) AJCC cancer staging handbook. From the AJCC cancer staging manual, 7th ed. Springer, New York

19. Hartl DM, Leboulleux S, Al Ghuzlan A, Baudin E, Chami L, Schlumberger M, Travagli JP (2012) Optimization of staging of the neck with prophylactic central and lateral neck dissection for papillary thyroid carcinoma. Ann Surg 255:777-783 
20. Gyorki DE, Untch B, Tuttle RM, Shaha AR (2013) Prophylactic central neck dissection in differentiated thyroid cancer: an assessment of the evidence. Ann Surg Oncol 20:2285-2289

21. McLeod DS, Sawka AM, Cooper DS (2013) Controversies in primary treatment of low-risk papillary thyroid cancer. Lancet 381 : 1046-1057

22. Bonnet S, Hartl D, Leboulleux S, Baudin E, Lumbroso JD, Al Ghuzlan A, Chami L, Schlumberger M, Travagli JP (2009) Prophylactic lymph node dissection for papillary thyroid cancer less than $2 \mathrm{~cm}$ : implications for radioiodine treatment. J Clin Endocrinol Metab 94:1162-1167

23. Sywak M, Cornford L, Roach P, Stalberg P, Sidhu S, Delbridge L (2006) Routine ipsilateral level VI lymphadenectomy reduces postoperative thyroglobulin levels in papillary thyroid cancer. Surgery 140:1000-1005

24. Podnos YD, Smith D, Wagman LD, Ellenhorn JD (2005) The implication of lymph node metastasis on survival of patients with welldifferentiated thyroid cancer. Am Surg 71:731-734

25. Shan CX, Zhang W, Jiang DZ, Zheng XM, Liu S, Qiu M (2012) Routine central neck dissection in differentiated thyroid carcinoma: a systematic review and meta-analysis. Laryngoscope 122:797-804

26. Zetoune T, Keutgen X, Buitrago D, Aldailami H, Shao H, Mazumdar M, Fahey TJ 3rd, Zarnegar R (2010) Prophylactic central neck dissection and local recurrence in papillary thyroid cancer: a metaanalysis. Ann Surg Oncol 17:3287-3293

27. Mulla M, Schulte KM (2012) Central cervical lymph node metastases in papillary thyroid cancer: a systematic review of imaging-guided and prophylactic removal of the central compartment. Clin Endocrinol (Oxf) 76:131-136

28. Choi JS, Kim J, Kwak JY, Kim MJ, Chang HS, Kim EK (2009) Preoperative staging of preoperative thyroid carcinoma: comparison of ultrasound imaging and CT. Am J Roentgenol 193:871-878

29. Barczyński M, Konturek A, Stopa M, Nowak W (2013) Prophylactic central neck dissection for papillary thyroid cancer. Br J Surg 100: 410-418

30. Hartl DM, Mamelle E, Borget I, Leboulleux S, Mirghani H, Schlumberger M (2013) Influence of prophylactic neck dissection on rate of retreatment for papillary thyroid carcinoma. World J Surg. doi:10.1007/s00268-013-2089-3
31. Ducoudray R, Trésallet C, Godiris-Petit G, Tissier F, Leenhardt L, Menegaux F (2013) Prophylactic lymph node dissection in papillary thyroid carcinoma: is there a place for lateral neck dissection? World J Surg 37:1584-1591

32. Randolph GW, Duh QY, Heller KS, LiVolsi VA, Mandel SJ, Steward DL, Tufano RP, Tuttle RM, American Thyroid Association Surgical Affairs Committee's Taskforce on Thyroid Cancer Nodal Surgery (2012) The prognostic significance of nodal metastases from papillary thyroid carcinoma can be stratified based on the size and number of metastatic lymph nodes, as well as the presence of extranodal extension. Thyroid 22:1144-1152

33. Wang TS, Evans DB, Fareau GG, Carroll T, Yen TW (2012) Effect of prophylactic central compartment neck dissection on serum thyroglobulin and recommendations for adjuvant radioactive iodine in patients with differentiated thyroid cancer. Ann Surg Oncol 19: $4217-4222$

34. Ricarte-Filho J, Ganly I, Rivera M, Katabi N, Fu W, Shaha A, Tuttle RM, Fagin JA, Ghossein R (2012) Papillary thyroid carcinomas with cervical lymph node metastases can be stratified into clinically relevant prognostic categories using oncogenic BRAF, the number of nodal metastases, and extra-nodal extension. Thyroid 22:575-584

35. Humphrey RW, Brockway-Lunardi LM, Bonk DT, Dohoney KM, Doroshow JH, Meech SJ, Ratain MJ, Topalian SL, Pardoll DM (2011) Opportunities and challenges in the development of experimental drug combinations for cancer. J Natl Cancer Inst 103:1222-1226

36. Barczynski M, Konturek A, Stopa M, Cichon S, Richter P, Nowak W (2011) Total thyroidectomy for benign thyroid disease: is it really worthwhile? Ann Surg 254:724-729

37. Shindo M, Stern A (2010) Total thyroidectomy with and without selective central compartment dissection: a comparison of complication rates. Arch Otolaryngol Head Neck Surg 136:584-587

38. Sosa JA, Bowman HM, Tielsch JM, Powe NR, Gordon TA, Udelsman R (1998) The importance of surgeon experience for the clinical and economic outcomes from thyroidectomy. Ann Surg 228:320-330

39. Giordano D, Valcavi R, Thompson GB, Pedroni C, Renna L, Gradoni P, Barbieri V (2012) Complications of central neck dissection in patients with papillary thyroid carcinoma: results of a study on 1087 patients and review of the literature. Thyroid 22:911-917 